\title{
Predicting Rice Grain Yield Using Soil Fertility Qualities: Inherent Soil Fertility Potential and Nutrient Availability (Case Study: Southern Half of Foumanat Plain in North of Iran)
}

\author{
Bahareh Delsouz Khaki , Naser Honarjoo , Naser Davatgar , Ahmad Jalalian ${ }^{1}$, \\ and Hosein Torabi Gelsefidi ${ }^{3}$ \\ ${ }^{1}$ Department of Soil Science, College of Agriculture, Khorasgan (Isfahan) Branch, Islamic Azad University, \\ Isfahan, Iran \\ ${ }^{2}$ Department of soil and water, Rice research institute, Rasht, Rasht, Iran \\ ${ }^{3}$ Department of Soil Science, College of Agricultural Sciences, Shahed University, Tehran, Iran
}

\begin{abstract}
Identifying and describing soil properties and their effects on crop yield can be a powerful decisionmaking tool in management systems. The fuzzy technique were used for better classification and combine sets of different soil properties into two soil fertility qualities: Inherent soil fertility potential (the thickness of plow layer, clay content, $C E C$, organic $C, E C$ and $p H$ ) and Nutrient availability (soil nutrient-supplying capacity for $N$, $P$ and $K)$. Results showed most of the area investigated had a moderate inherent fertility potential and were in low class of nutrient availability for intensive rice production. Due to their lower inherent potential and nutrient content, most of the study area in the western parts may not be suitable for further intensification of rice production in this status. Especially low available $K$ seems to be the major constraint to high rice yields. Further yield increases will require improved adjustment of $P$ fertilizer rates according to the soil $P$ status. According to the results, better nutrient management practices is necessary. Furthermore, the simultaneous method (enter method) for regression analysis showed that the grain yield $(\mathrm{Yg})$ was linearly correlated with the two soil fertility qualities as $Y g=3774.207+556.382(I P)+172.595(N A)(r 2=0.32, P<0.01)$. The coefficient on IP was the highest for Yg. Therefore, Inherent soil fertility potential was the most dominant yield determinant.
\end{abstract}

Keywords: Soil, Fertility, Quality, Rice, Fuzzy, Prediction.

\section{Introduction}

Considering growing population, improving the crop productivity is highly required. Moreover evaluating soil fertility and productivity in order to increase production can be a fundamental process and acquiring detailed knowledge about the soil fertility status is a prerequisite for assessing the long-term impact of modern, intensive rice production technologies on paddy fields (Dobermann and Oberthur, 1997)

Soil fertility deals with nutrient status and ability of soil to supply nutrients for optimum plant growth. However, the optimum nutrient status alone will not ensure soil productivity (Sumner, 2000). Soil productivity is defined as the capability of the soil for producing a quantified plant production by considering field and laboratory diagnostic techniques (Davatgar et al., 2012).

Fuzzy set theory originated by Lotfi Zadeh (1965). Fuzzy systems provide a rich and meaningful improvement, or extension of conventional logic (McBratney and Odeh, 1997). Research showed fuzzy methods produce contiguous areas and reject less information at all stages of the analyses. They are much better methods for classification of continuous variation. Also joint fuzzy membership functions (JFMF) can be used to combine sets of different soil properties into more general indices of soil quality (Burrough et al.,1992).

Dobermann and Oberthür (1997) produced the soil fertility map for irrigated Riceland in the Philippines by using fuzzy system. They showed a combination of fuzzy membership functions with Monte Carlo simulation to produce maps of membership values for three soil fertility classes and two multivariate soil fertility qualities. Davatgar et al., (2012) studied the delineation of site specific nutrient management zones for a paddy cultivated area based on soil fertility using fuzzy clustering and concluded that cluster analysis by reducing withinzone variability provided an opportunity for farmers to adopt site-specific nutrient management. 
Rice (Oryza sativa L.) is an important food crop for a large proportion of the world's population (Fageria et al., 2003). It also is considered as a strategic crop in north of Iran and second staple food after wheat in the country (Khush 1993) While, nutrient management for paddy fields in Iran is based on typical and uniform recommendations for large regions. This results in over-application in area with high nutrient levels and underapplication in area with low nutrient levels (Davatgar et al., 2012) Therefore, for improvement in management practices, it is necessary to identify which soil properties control rice grain yield variability in a field as well as what is the situation of these properties in the area. Hence, The objectives of the study were: (1) to indicate the soil nutrients and inherent fertility potential of a paddy cultivated area in Southern Half of Foumanat Plain in north of Iran, (2) to identify areas suffering from specific soil limitations to rice growth, (3) Predicting rice grain yield using two soil fertility qualities: inherent soil fertility potential and nutrient availability.

\section{Materials and methods}

\subsection{Site Description, Soil Sampling and Measurements}

This study was conducted on an area of 24,000 ha paddy fields located in southern half of foumanat plain. The region is located in a flat alluvial soils inside two city (fouman and shaft) of Guilan province, in north of Iran with $49^{\circ} 15^{\prime} 40^{\prime \prime}$ to $49^{\circ} 28^{\prime} 5^{\prime \prime}$ east longitude and $37^{\circ} 7^{\prime} 48^{\prime \prime}$ to $37^{\circ} 15^{\prime} 56^{\prime \prime}$ north latitude. An overview of the boundary of the study area is given in figure 1. Sampling points are well scattered in paddy cultivated area, except somewhere due to existence of a road and urban area. The region is sub humid with mean annual temperature of $20.5^{\circ} \mathrm{C}$ and mean annual precipitation of about $1200 \mathrm{~mm}$. The soil texture ranges from siltyloam to clay. The soil in the area is classified as alfisol and inceptisol according to USDA Soil Taxonomy (2003). Full irrigation has been provided for more than 20 years and the land use of the study area is mainly rice paddy fields. Hashemi cultivar, a high quality and semi dwarf rice (Oryza sativa), is cultivated in irrigated lowland paddy fields of the study area. Land preparation (includes plowing, puddling and harrowing) was performed 30 to 7 days before transplanting annually in early spring. The study area was fertilized with $60 \mathrm{~kg}$ ha $146 \mathrm{~N} 2$ (as urea). Although, some farmers use $45 \mathrm{~kg}$ ha P2O5 (as triple super phosphate). However, a few farmers use 100 $\mathrm{kg} \mathrm{K} 2 \mathrm{O}$ ha (as potassium sulfate).Soil samples were taken before fertilizing and planting the fields. Because more than $90 \%$ of total root length of irrigated rice is located within the topmost 0-20 cm soil (De Datta et al., 1988a), thick ness of the plow layer (Ap horizon) measured and was papered and soil samples were collected from each puddled top soil horizon of 119 points. Teams of 2 persons collected soil samples of nearly equal quantities from each site. The location coordinates of each sampling site were recorded using global positioning systems (GPS) unit. Soil samples were kept in plastic bags, air-dried and ground to pass through a 2$\mathrm{mm}$ sieve before chemical and physical analysis. The electrical conductivity (EC), was determined from the saturation soil paste extract by ECmeter device. Particle size analysis for soil texture determined by hydrometer method. Soil pH was measured in 1:1 (W/W) soil/water suspension, organic C (OC, Walkley-Black), cation exchange capacity (CEC, Na-Oac method, pH 8.2), total nitrogen (TN, Kjeldahl), available phosphorous (AP, Olsen), available potassium (AK, NH4OAC method, $\mathrm{pH}$ 7). Yield data and general agronomic information were collected from 119 farmers' fields in the 2013 harvest time. These sampling locations were chosen according to soil sampling points and all farmers grew irrigated rice (Oryza sativa L.). In about center of each field, one $0.5 * 0.5 \mathrm{~m}$ quadrate was selected to obtain plant. Then the hollow and plum grain were separated carefully and next the plum grains weights determined after 48 hours in $70{ }^{\circ} \mathrm{C}$.

\subsection{Descriptive Statistics}

The soil properties were analysed using descriptive statistics. The descriptive statistics including mean, standard deviation (SD), minimum, maximum and coefficient of variation (CV) were calculated for each properties in SPSS 17.0 (SPSS Inc., Chicago IL). The mean was used to determine the average distribution of the variables. The standard deviation(SD) shows how the variable deviates from the mean and the coefficient of variation $(\mathrm{CV})$ shows the percentage of variation of the standard deviation from the mean. 


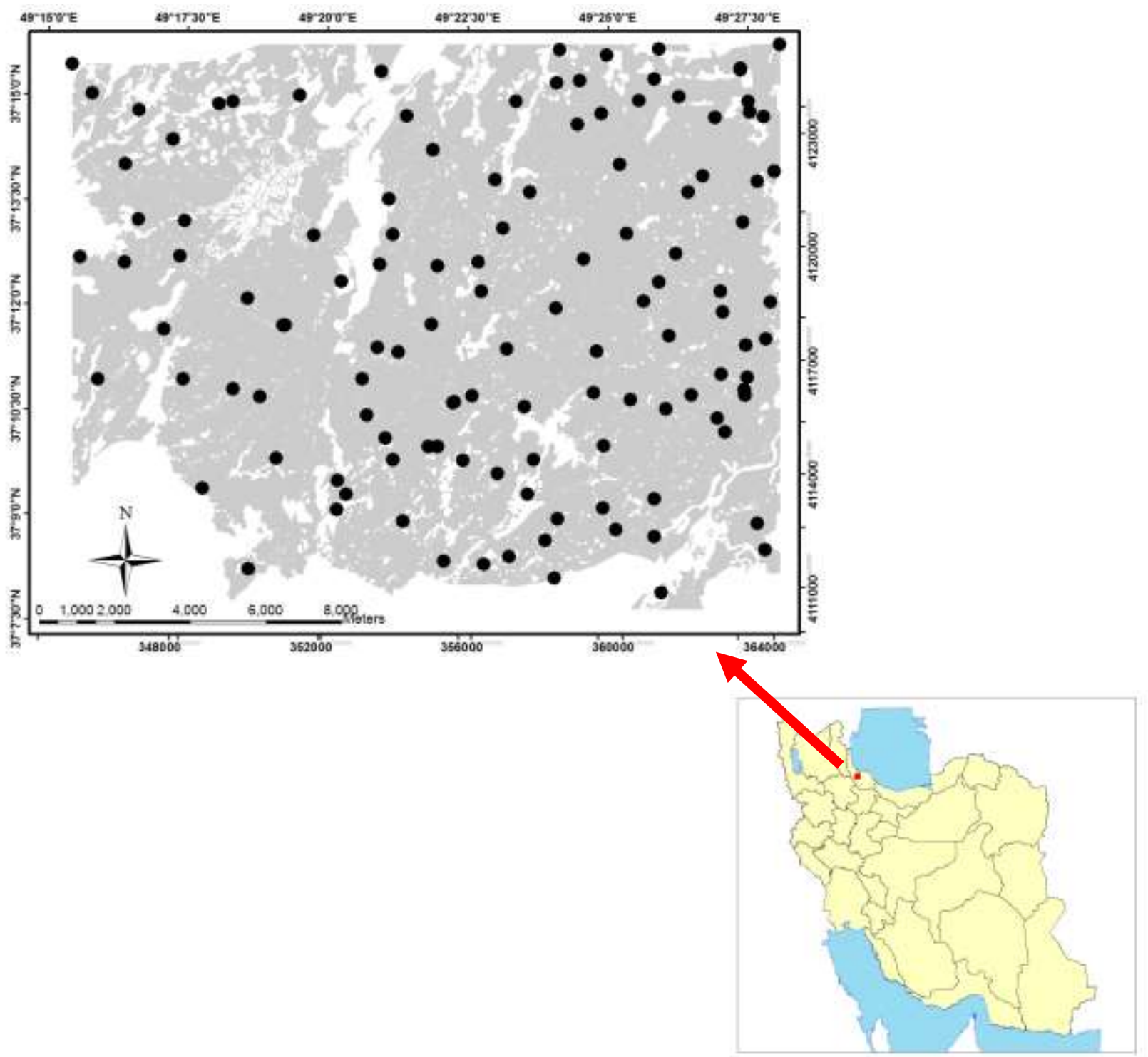

Fig. 1: Location of the study area and spatial distribution of sampling points in paddy fields of southern half of foumanat plain in north of Iran.

\subsection{Fuzzy Membership Function}

A fuzzy membership function (FMF) converts attribute values $\mathrm{Z}$ to fuzzy membership function values $(\mathrm{FMFz})$ on a continuous scale ranging from 0 to 1 , with 1 representing full membership and 0 no membership to the set. Dobermann and Oberthur (1997) defined three categories for each soil property:

Class 1, low fertile, severe constraint to nutrient uptake and high rice yield $(\mathrm{Z}<\mathrm{bl})$,

Class 2, medium fertile, possible constraint to nutrient uptake and high rice yield (b $1<\mathrm{Z}<\mathrm{b} 2$ ),

Class 3, high fertile, no constraint to nutrient uptake and high rice yield $(\mathrm{Z}>\mathrm{b} 2)$.

They used a sigmoid FMF, which in its symmetrical form can be written as: 


$$
\begin{array}{ll}
\mathrm{FMF}_{Z}=\frac{1}{\left(1+\left(\frac{\left(Z-b_{1}-d\right)}{d}\right)^{p}\right)} & \text { for } Z<\left(b_{1}+d\right) \\
\mathrm{FMF}_{Z}=1 & \text { for }\left(b_{1}+d\right) \leq Z \leq\left(b_{2}-d\right) \\
\mathrm{FMF}_{\mathrm{Z}}=\frac{1}{\left(1+\left(\frac{\left(Z-b_{2}+d\right)}{d}\right)^{p}\right)} & \text { for } Z>\left(b_{2}-d\right)
\end{array}
$$

where $b_{1}$ and $b_{2}$ are the lower and upper class limits, $d$ is the dispersion value, $p$ is the power value (determining curve slope). Because the objective of our study was mapping the potential for high fertile, in this study was considered to class 3 so we used just the third equal for soil properties thus instead of $b_{2}$, it shown as $b$ in table 1 . The b values were determined by expert knowledge procedure.

TABLE I: Definitional criteria for membership model and d values

\begin{tabular}{ccc}
\hline \hline Soil properties & B & $\mathrm{d}$ \\
\hline Ap horizon $(\mathrm{cm})$ & 20 & 2.5 \\
clay content (\%) & 35 & 3 \\
Organic C (g kg- J $)$ & 2 & 0.2 \\
CEC (cmol kg- i ) & 20 & 2 \\
Totat-N (\%) & 0.2 & 0.02 \\
Available P (p.p.m) & 12 & 2 \\
Available K (p.p.m) & 160 & 12 \\
pH of paste & 7 & 0.6 \\
EC (dS m $\left.{ }^{-1}\right)$ & 2 & 0.2 \\
\hline \hline
\end{tabular}

\subsection{Soil Qualities Calculation}

Joint fuzzy membership functions (JFMF) can be used to combine sets of different soil properties into more general indices of soil quality (Burrough et al., 1992). As Dobermann and Oberthur (1997), we considered mapping of two soil fertility qualities.

(1) Inherent soil fertility potential: general physical and physico-chemical soil conditions, which are mainly influenced by the soil type. Suitable indicators of the inherent potential are, for example thickness of the plow layer (Ap), clay content (Clay), CEC, organic C (OC), EC and pH Changes of such soil properties occur only slowly, but intensive rice production may affect some of them.

Model 1: all stable soil properties are favourable for intensive rice cropping (high inherent potential, Ap $\geq$ 20 and $\mathrm{Clay} \geq 35$ and $\mathrm{OC} \geq 2$ and $\mathrm{CEC} \geq 20, \mathrm{EC} \leq 2$ and $\mathrm{pH}=6-7$ )

$$
\mathrm{JMF} I P h i g h=\mathrm{MIN}\left(\mathrm{FMF}_{\mathrm{Ap}}, \mathrm{FMF}_{\mathrm{Clay}}, \mathrm{FMF}_{\mathrm{OC}}, \mathrm{FMF}_{\mathrm{CEC}}, \mathrm{FMF}_{\mathrm{EC}}, \mathrm{FMF}_{\mathrm{pH}}\right)
$$

(2) Nutrient availability: soil nutrient-supplying capacity for N, P and K. These elements were measured as readily available fractions. They are very dynamic and much affected by management practices.

Model 2: inherent soil supply of all nutrients is adequate for rice yields (medium-high nutrient availability, $\quad \mathrm{N} \geq 02$ and $\mathrm{P} \geq 12$ and $\mathrm{K} \geq 160$ )

$$
\mathrm{JMF} \text { NA high }=\mathrm{MIN}\left(\mathrm{FMF}_{\mathrm{N}}, \mathrm{FMF}_{\mathrm{p}}, \mathrm{FMF}_{\mathrm{K}}\right)
$$

In model 1 (Eq. (2)), for example, all conditions have to be fulfilled until a soil matches the requirements of an inherently very productive soil.

According model 1 and model 2 the two JMF were calculated for each sample, then using the JMF values, 
the two soil fertility quality maps was produced using IDW method in GIS(9.3) then classified into four class: very low $(\mathrm{JMF}<0.25)$, low(JMF: 0.26-0.50), moderate(JMF: 0.51-0.75) and high(JMF>0.76).

\subsection{Multiple Regression Analysis}

The general purpose of multiple regression (the term was first used by Pearson, 1908) is to learn more about the relationship between several independent or predictor variables and a dependent or criterion variable. Multiple regression procedures will estimate a linear equation of the form shown in Equation (4), where $\mathrm{Y}$ represents estimated rice grain yield, $b_{0}$ to $b_{n}$ are coefficients, $F_{1}$ to $F_{n}$ are the latent variables, and $\varepsilon$ represents residual error.

$$
\mathrm{Y}=\mathrm{b}_{0}+\mathrm{b}_{1} \mathrm{~F}_{1}+\mathrm{b}_{2} \mathrm{~F}_{2}+\ldots+\mathrm{b}_{\mathrm{n}} \mathrm{F}_{\mathrm{n}}+\varepsilon
$$

The standard method of selecting a regression equation is simultaneous (a.k.a. the enter method) in which all independent variables are entered into the equation at the same time. This is an appropriate analysis when dealing with a small set of predictors and when the researcher does not know which independent variables will create the best prediction equation. Each predictor is assessed as though it were entered after all the other independent variables were entered, and assessed by what it offers to the prediction of the dependent variable that is different from the predictions offered by the other variables entered into the model. Therefore, the multiple regression analysis was performed using the two soil fertility qualities (inherent soil fertility potential and nutrient availability) and rice grain yield data. It was done in SPSS 17.0(SPSS Inc., Chicago IL).

\section{Results and Discussion}

\subsection{Exploratory Analysis of Data}

Descriptive statistics for soil properties are given in Table 2. The soil was acid to slightly alkaline, with $\mathrm{pH}$ ranging from 5.49 to 7.53 . The mean OC was $2.48 \%$. According to the study by Doberman and Fairhurst (2000), the mean soil OC content in this area was high for rice growth. The mean soil $\mathrm{N}$ and $\mathrm{P}$ were considered sufficient for rice growth, with a value of $0.23 \%$ and $15.64 \mathrm{mg} \mathrm{kg}-1$, respectively. The mean $\mathrm{K}$ content was low and would not meet the need for rice growth. Thickness of the plow layer (Ap) was mostly in the range of 10 to $22 \mathrm{~cm}$. The restriction to root growth is possible in shallow plow layer less than $15 \mathrm{~cm}$. Moreover, soil volume available for nutrient uptake is limited for this condition. The high value for $\mathrm{CV}$ of available $\mathrm{P}$ and $\mathrm{K}$ showed that fertilization, land use pattern and soil management practices are heterogeneous. The values of $\mathrm{CV}$ in soil nutrient elements were larger than inherent soil fertility potential properties (except EC). This indicated that soil nutrients in the study area had considerable spatial variability that can satisfy preconditions for soil nutrient management zones and suggested that variable rate fertilization management may be helpful to improve rice production in the study area.

TABLE II: Descriptive statistics of soil properties and rice grain yield in study area.

\begin{tabular}{cccccc}
\hline \hline Soil properties & Min & Mean & SD & Max & CV (\%) \\
\hline pH & 5.49 & 6.6254 & 0.52463 & 7.53 & 7.92 \\
OC $(\%)$ & 1.0 & 2.48 & 0.7173 & 4.5 & 28.96 \\
CEC (cmole kg-1) & 10 & 29.46 & 7.155 & 47 & 24.29 \\
EC (dS m $\left.{ }^{-1}\right)$ & 0.12 & 1.2674 & 0.51347 & 2.71 & 40.51 \\
Clay (\%) & 6 & 39.88 & 9.778 & 56 & 24.52 \\
Ap (cm) & 10 & 15.98 & 2.36 & 22 & 14.77 \\
$\mathrm{~N}(\%)$ & 0.11 & 0.23 & 0.05969 & 0.4 & 25.86 \\
$\mathrm{P}(\mathrm{mg} \mathrm{kg}-1)$ & 2 & 15.64 & 12.902 & 72 & 82.49 \\
$\mathrm{~K}\left(\mathrm{mg} \mathrm{kg}^{-1}\right)$ & 55 & 139.23 & 54.661 & 350 & 39.26 \\
$\mathrm{Yg}\left(\mathrm{kg} \mathrm{ha}^{-1}\right)$ & 2853 & 4490 & 394.04 & 4998 & 8.8 \\
\hline \hline
\end{tabular}

OC: organic carbon; CEC: cation exchange capacity; Ap: top soil depth; N: total nitrogen;

$\mathrm{P}$ : available phosphorous, $\mathrm{K}$ : available potassium, Yg: rice grain yield. 


\subsection{Soil Fertility Constraints to Intensive Rice Cropping}

About $38.66 \%$ of all samples analyzed had minimum value (JMF) due to $\mathrm{k}$. Thickness of the plow layer caused $19.33 \%$ of minimum values. Both Total $\mathrm{N}$ and CEC resulted $1.68 \%$ of minimum values. Organic $\mathrm{C}$ and Clay content were the minimum value's reason in just 3.36\% of all sample points. The proportion of EC, $\mathrm{pH}$ and $\mathrm{P}$ in minimum values was $4.2 \%, 7.56 \%$ and $23.53 \%$ respectively. Thus the most limitations among inherent potential factors caused by thickness of top soil and in case of nutrient availability factors by $\mathrm{k}$.

\subsection{Inherent Potential and Nutrient Availability}

About $92 \%$ of the study points had inadequate soil supply of one or more nutrients and about $8 \%$ of points had not any limitation for inherent potential factors as well as about $8 \%$ of points had not any limitation for nutrient availability factors. The average membership values for Inherent potential and nutrient availability were 0.6 and 0.35 respectively.

Most of the area investigated had a moderate inherent fertility potential and were in low class of nutrient availability for intensive rice production. Due to their lower inherent potential and nutrient content, most of the study area in the western parts may not be suitable for further intensification of rice production in this status.

Almost all the land had limitations due to moderate soil status of one or more nutrients but because the study area is part of the most productive riceland in the country, the need for better nutrient management practices is clear. It should be noted the two soil quality maps produced in view of class 3 .

\subsection{Multiple Regression Analysis}

119 samples were used for the multiple regression model's development. The multiple regression analysis was performed using the two soil fertility qualities (inherent soil fertility potential and nutrient availability) and rice grain yield data.

Because of using simultaneous method (enter method), each of two soil fertility qualities were included in the regression equation. The result of the multiple regression analysis is presented in equation (5) where $\mathrm{Yg}$ is rice grain yield $\left(\mathrm{kg} \mathrm{ha}^{-1}\right)$.

$$
\mathrm{Yg}=3774.207+556.382(\mathrm{IP})+172.595(\mathrm{NA})\left(\mathrm{r}^{2}=0.32, \mathrm{P}<0.01\right)(5)
$$

The most important term in the regression equation for rice grain yield prediction was the inherent soil fertility potential (IP), which had the largest coefficient. According to the results, the most controlling soil properties were identified as thickness of the plow layer (Ap horizon), clay content, organic matter (OC), cation exchangeable capacity (CEC), the electrical conductivity (EC) and Soil $\mathrm{pH}$ for grain yield. Furthermore, determination coefficient of relationship between yield and the two soil fertility qualities (IP and NA) was 0.32. Therefore the developed regression equations for prediction of rice grain yield explained $0.32 \%$ variance in rice grain yield. So the remaining variance may belong to no measured variables like micronutrient variability and other management effects such as irrigation pattern within the field. Furthermore, the prediction capability of these models, the latent variables that are significantly related to yield, can be useful to understand the reasons for grain-yield variability, and this understanding can, in turn, be used to manage better for crop production.

\section{Conclusions}

Nutrients have become major yield-limiting factors in many farms of the study area. Of the soil fertility indicators measured in this case study, low available $\mathrm{K}$ seems to be the major constraint to high rice yields. This is because of lower soil K-supplying power and insufficient application of mineral $\mathrm{K}$ fertilizer. Farmers generally applied insufficient amounts of fertilizer $\mathrm{K}$ to maintain a positive $\mathrm{K}$ balance Therefore, $\mathrm{K}$ management is critical for keeping rice yield at high level. In case of $\mathrm{P}$ management, further yield increases will require improved adjustment of $\mathrm{P}$ fertilizer rates according to the soil $\mathrm{P}$ status. Thus Monitoring soil fertility at regional scales is necessary to assess changes in the resource base over time.

The fuzzy methodology used in the study is one efficient way to account for the uncertainties associated with such activities, but approaches such as dynamic adjustment of fuzzy membership functions based on objective criteria should receive further attention. 
The simultaneous method (enter method) for regression analysis identified the inherent soil fertility potential (IP), as the dominant indicator for predicting grain yields because of the largest coefficient. Also the results indicated that improvement of the two qualities (IP and NA) are important to increase crop productivity. Therefore, improvement in thickness of the plow layer (Ap horizon), clay content, organic matter, cation exchangeable capacity, the electrical conductivity and Soil $\mathrm{pH}$ will increase the grain yield of rice. The results of this study are only applicable to the site studied and to other sites in the same region with similar topography, climate, soils, and management.

\section{Acknowledgements}

This research was funded by the Rice Research Institute (IRRI) in Rasht. We thank for their assistance with soil sampling and soil analyses and providing.

\section{References}

[1] Burrough, P.A., MacMillan, R.A., Van Deursen, W.P.A., 1992. Fuzzy classification methods for determining land suitability from soil profile observations and topography. J. Soil Sci. 43, 193-210.

http://dx.doi.org/10.1111/j.1365-2389.1992.tb00129.x

[2] Davatgar N, Neishabouri MR, Sepaskhah AR. 2012. Delineation of site specific nutrient management zones for a paddy cultivated area based on soil fertility using fuzzy clustering. Geoderma 173:111-118

http://dx.doi.org/10.1016/j.geoderma.2011.12.005

[3] Doberman, A., Fairhurst, T.H., 2000. Rice: Nutrient Disorders \& Nutrient Management. International Rice Research Institute, Philippines.

[4] Dobermann, A., Oberthur, T., 1997. Fuzzy mapping of soil fertility-a case study on irrigated rice land in the Phillipines. Geoderma 77, 317-339.

http://dx.doi.org/10.1016/S0016-7061(97)00028-1

[5] Fageria NK, Slaton NA, Baligar VC. 2003. Nutrient management for improving lowland rice productivity and sustainability. Advances in Agronomy 80, 63-152.

http://dx.doi.org/10.1016/S0065-2113(03)80003-2

[6] Khush, G.S., 1993. Varietal Needs for Different Environments and Breeding Strategies. In: New Frontiers in Rice Research, Muralidharan, K. and E.A.

[7] Lotfi Zadeh LH (1965) Fuzzy sets. Infor Control. 8: 338- 353.

http://dx.doi.org/10.1016/S0019-9958(65)90241-X

[8] Mc Bratney, A.B., Odeh, I.O.A., 1997. Application of fuzzy sets in soil science: fuzzy logic, fuzzy measurement and fuzzy decisions. Geoderma 77, 85-113.

http://dx.doi.org/10.1016/S0016-7061(97)00017-7

[9] Sumner, M.E., 2000. Handbook of Soil Science. CRC press. 